\title{
Transformation of the real estate market on the basis of use of the blockchain technologies: opportunities and problems
}

\author{
Nadezhda Kalyuzhnova, ${ }^{1, *}$ \\ ${ }^{1}$ Irkutsk State University, 664003, Karla Marksa str., 1, Irkutsk, Russia
}

\begin{abstract}
The real estate market is influenced by the global growth trends, such as the growth of the transaction costs and new technologies of the fourth industrial revolution. The types of the transaction costs of the real estate market are analyzed in the paper. The characteristics of the blockchain as a new information technology that allows reducing transaction costs are considered. The essence of the blockchain as a value-communication technology that allows transferring not only information, but also value using mobile networks and the Internet, is substantiated. The types and classification of the blockchains are considered. The directions of real estate transformation on the basis of introduction of the blockchain technologies are shown. Some unresolved issues, as well as the dangers and challenges of the development of the blockchain technologies, are indicated in this article.
\end{abstract}

The real estate market is one of the most complex and important elements of the market system. Real estate is a valuable distributed resource that solves different tasks. It satisfies the basic human need for living space and security, and it is also the basis of many types of business, a part of the national wealth, and a source of the budget revenues. The total value of assets of the international real estate market is estimated at \$217 trillion, and in 2017 the volume of transactions was of $\$ 1.4$ trillion [1]. This market creates a significant part of the added value of regions. Thus, in 2016, the volume of operations with real estate, leasing and rendering services in the Irkutsk region amounted to 78182.4 million rubles or $7.3 \%$ of the gross added value of the region that is more than in agriculture $(6 \%)$ or the construction industry $6.3 \%$ ) [2].

The real estate market is influenced by the global trends, of which we distinguish two ones - the growth of transaction costs and the development of technologies.

The increase of the transaction costs in the economy is a consequence of the development of technology and the growth of the diversity of products, activities and interrelations in the economy. The value of the transaction sector can be estimated approximately by the share of the service industries, in which the largest share falls on the financial, trade, insurance, marketing and other services serving market transactions. In 2016, the service sector amounted to $62.8 \%$ in the gross world product of 75.27 trillion [3]. This trend also applies to the Russian regions. In 15 regions, the share of services ranged from $61 \%$ to $73 \%$, and in Moscow it was more than $75 \%$ [4].

*Corresponding author: 2010nyk@ mail.ru 
The real estate market has a complex structure of participants, to which belong sellers and buyers of real estate, intermediaries, developers, builders, tenants; landlords; real estate owners, state bodies registering real estate transactions; organizations involved in the registration and financing real estate transactions: notaries, bureaus of technical inventory, registration chambers, consultants and appraisers, investors, lending institutions, borrowers, and credit brokers. The transaction for the purchase and sale of the property takes at least 15 days, and, as a rule, even more. A complex system of interrelations between the participants forms a high share of the transaction costs in the price of real estate.

The transaction costs of the real estate market are also caused by the information asymmetry referring to the real estate objects. There are a large number of frauds associated with the ability to manipulate with ownership of the objects. All this causes a high level of transaction costs for establishing trust between counterparties in this market.

The purpose of this research is to study the possibilities of reducing the transaction costs of the real estate market using distributed registry technology.

For the study, the provisions of the institutional economic theory of the transaction costs applied to the real estate market have been used. The possibilities of using distributed registry technology, also called blockchain, to reduce transaction costs on the real estate market are dealt with. The problems of the implementation of the blockchain technology are considered in the article.

The classical definition of the transaction costs belongs to T. Eggertsson, who defined them as "the costs that arise when individuals exchange the ownership rights to economic assets and secure their exclusive rights" [5]. D. North described the transaction costs as "the costs of assessing the useful properties of an object and the costs of enforcing rights and compelling to comply with them". [6] Any costs associated with the coordination and interaction of economic entities can be classified as transaction costs.

The transaction costs on the real estate market in terms of the five-factor division of the transaction costs include the following:

1. Information retrieval costs - the time and money that buyers and sellers spend searching for information on objects, comparing prices, advertising, visits, and views. Real estate companies take on some of these services, so the transaction costs turn into the incomes of real estate firms that cover not only transaction costs, but the profits of these companies. The commission of realtors makes from $1 \%$ to $6 \%$ of transactions. Non-transparent information, inaccurate reviews, and overstated commission of intermediaries are the problems.

The rental market uses centralized services that simplify the search, but also take high commission fees. For example, the short-term lease platform Airbnb charges a commission of up to $12 \%$ from the guests and up to $3 \%$ from the homeowners, mainly because of the need to pay for the work of more than 3,500 employees. Similarly, Booking and Expedia charge commissions ranging from $15 \%$ to $30 \%$ from the affiliated hotels to the amount of booking for each transaction [6].

2. The costs of negotiations and conclusion of transactions. This is the cost of negotiations, time and costs for travels, calls, hospitality, paper, and the organization of bidding in the case of sale at auction, obtaining information, and drafting a contract. The average term for the sale of an apartment in Hungary is 2 months, in Germany - 3 months, in Moscow - 4 months [7].

3. Measurement costs. The real estate market is one of the most nontransparent and information asymmetric markets, which can be attributed to the G. Akerlof's market of "lemons". The quality of real estate includes the quality of materials, the strength and safety of the facility and utilities, the location, convenience, design, and aesthetics of the facility. All these features are difficult to unequivocally assess before buying or renting an object. Because of this, buyers often use surrogate ratings, such as reviews, reputation of the developer, which is provided, inter alia, by advertising, increasing the transactional costs. 
4. The costs of specification and protection of the property rights. This includes time inputs (usually it is an expensive resource for real estate buyers) and funds for legal due diligence and registration of the real estate purchase transaction. This is the cost of a notary and a registration of the property rights with the Federal registration service. When using mortgage or other credit resources, this includes time and costs for interaction with banks for the preparation of collateral and a loan agreement, for the preparation of valuation documents and the services of appraisers, documents for the bureau of the technical inventory, and insurance. In Russia, the time of the Russian register service's interaction with the bank is at least 15 days.

The real estate market is one of the most criminal ones; there is a large field of deliberate abuse of bargainers. It is noted that $6-8 \%$ of all real estate transactions have signs of different frauds, which are more than 40 [8]. For many real estate objects, the property rights are not clarified, there are problems of double sale of land and housing. Accordingly, significant costs go for judicial protection of the rights of real estate market participants in case of their violation, the restoration of rights, as well as the maintenance of judicial and state bodies that ensure law and order on this market.

5. The costs of the opportunistic behavior. These costs are related to the evasion of obligations under the contracts, such as the contracts for the shared construction, repair, registration of rights, and the costs of restoring the rights of defrauded buyers.

Thus, the real estate market, being part of the transactional sector of the economy, contains a huge sector of the transaction costs within itself, the reduction of which is the task for optimizing this market.

Blockchain, the technology of the distributed registry, is one of the breakthrough technologies for the transition to the fourth industrial revolution. If the first two industrial revolutions radically changed the sphere of production, the third one prepared the basis for changing the ways of communication between people. Personal computers and the Internet of the third industrial revolution made it possible to instantly transfer information to different ends of the world where the Internet is available, to conduct negotiations remotely via Skype, Viber and other software that reduced the costs of searching for information and negotiations.

K. Schwab connects the fourth industrial revolution with a complex of technologies, including information and communication, which add mobility to computers and the Internet [10]. Among them, a breakthrough innovative technology is the invention of a way of transferring not only information, but also the value, which in the technology of the blockchain is transferred in the form of digital currency. K. Sinner calls it WalueWeb - the value Internet [11].

Let us determine the main characteristics of the blockchain technology, important from the point of view of the possibility of reducing costs for the market transactions.

Blockchain is a distributed, decentralized registry transactions of $\mathrm{p} 2 \mathrm{p}$, supported by a network of electronic devices that ensure its relevance and inclusion of new transactions in the network by validating, i.e. the confirmation of transactions. Each transaction has a timestamp and its own unique code. The transaction chain exists simultaneously on millions of computers, which makes it practically impossible to change the content of a transaction once committed. The change in the content of the transaction leads to the formation of a new transaction and a new hash inherent to it. Digital currency is the mechanisms that ensure transactions by forming cryptographic labels of transactions (hashes) that the network participants receive as a reward for maintaining the network and validation of transactions.

The revolutionary change is in the fact that for the confirmation of transactions and the transfer of information, there is no need for the third party to be trusted by the participants of the transaction. Trust in the system of the blockchain transactions is provided by the mechanism of cryptographic confirmation of transactions by forming a 32-bit unique code for each transaction. It is formed from the previous hash and the code of the newly made 
transaction by the automatic mathematical conversion into a new hash code. Thus, the issues of possible double spending of money and confirmation of the truthfulness of the transaction, which different intermediaries of the transactions that were intended to solve, are solved.

Blockchain provides confidence in the transactions not because there is a party certifying the integrity of the participant, or the content of the transaction, but because the very method of confirming a transaction does not require the confidence of either participants, or the content of the transaction. The confirmation is executed with the help of calculations and cryptographic encryption, which is supported by the machine money created in this process - the digital (crypto) currency, the first of which is bitcoin. The completed transaction remains forever fixed in the blockchain. Crypto currencies, which are the side effects of this process, are self-propelled because of their intrinsic properties, and acquire an independent value.

Any chain of transactions, fixed in some kind of registry, can be called the blockchain, but the revolutionary transforming essence of the blockchain is connected with the invention of the opportunity to form and transmit digital currencies - virtual machine money - through the computer devices and the Internet. With the emergence of the first bitcoin, it became possible to send through mobile devices not only information, but also value, and such Internet becomes not only information, but also value-communication technology. This should be especially noted, since in general the attitude to the blockchain is positive, but the attitude to bitcoin and other digital currencies is either vague or even negative, that originates in the institutional uncertainty in the status of digital currencies in the sphere of regulation in the world and in Russia. However, it does not negate the fundamental value of the crypto currency as the basis of the blockchain value-communication technology.

The features of the blockchain technology that ensure the security and protection of information are the following: the authentication of the individual, the integrity of transactions, the impossibility to reject transactions, the confidentiality of transactions, the independence from the state of individual hubs, and the inability to change information without the approval of the network participants [12].

Blockchain is a technology capable in the long term to solve the most important economic issue that is the problem of trust of the transaction participants, on the new, technological basis.

The problem of trust is a fundamental economic problem posed by F. Fukuyama. Fukuyama gives extremely important role to this issue, arguing that "national wealth, as well as competitiveness, is conditioned by such a single all-encompassing characteristic as the level of trust inherent in society" [13]. Different researches show that trust affects economic growth [14] and the competitiveness of countries and regions [15].

Confidence on the real estate market is provided in the following ways:

1. Confirmation of the transaction. All currently available intermediaries of financial and non-financial transactions - banks, payment system operators, state registration and control bodies, notary, etc., - confirm the transaction with their documents.

2. Verification of the completeness and correctness of the information specified in the transaction documents by lawyers, banks, and registration authorities.

3. Making the legal status to the property rights. In the legislation of many countries, there are special requirements for the registration of the property rights for real estate. To register rights, so called Torrens title system is used, in which the unconditional ownership of the beneficiary for the real estate property is guaranteed by a record in the state real estate registry. Transfer of ownership is made by making changes in the records of the register, on the basis of documents on the transaction. The responsibilities for keeping the register are delegated to the state bodies, which should ensure impartiality and its correct conduct [16].

With the increase in the chain of participants, the issue of trust, or, more accurately, of distrust, is aggravated. Buyers and sellers, not trusting each other, are compelled to address 
intermediaries; therefore, the abuse of trust is possible. The intermediaries - realtors and banks - recheck the documents many times, and changes in the documents lead to the repeated checks and reconciliations.

Blockchain allows to reliably recording transactions in the absence of a central trust management, and make it without intermediaries. The global consequences of this innovation are a reduction in the number of intermediaries in the transactions, a decrease in the transaction costs of market activities and the emergence of the new opportunities, also in real estate. William Mougayar writes in this regards: "If the blockchain is a new way to implement trusted transactions without trusted intermediaries, soon we will finish with intermediary institutions" [17].

Let us consider these possibilities in more detail.

By the complexity and importance of the services and tasks provided, the four levels of the blockchain are distinguished, with different possibilities [18]:

1.0. Solves the problem of increasing the efficiency and reducing the transaction costs of financial payments through the use of crypto currency.

2.0. Solves the problem of fixing contracts. Promotes the decentralization of markets, provides for the storage of documents, and ensures the opportunity to create decentralized autonomous organizations, automatic markets, and decentralized financing.

3.0. Serves as the basis for the organization of activity: provides proof of the property rights, improves the efficiency of public administration, and ensures decentralization of management,

4.0. Serves as a basis for the efficiency and coordination in the society in different directions.

In accordance with the indicated levels, there will be the following directions of using the blockchain on the real estate market:

- The use of digital currency in the real estate transactions;

- The transfer of document circulation on the transactions with real estate on the blockchain;

- The decentralization of sales through tokenization;

- The transfer of the real estate registry to the blockchain.

It should be noted that digital currencies and tokens are currently not regulated by the Russian law, which, however, does not prohibit them. Nevertheless, there is a progress towards the legitimization of crypto currencies and tokens. In the draft law submitted to the State Duma on March 26, 2018, it was proposed to introduce into the Civil Code provisions regulating the legal relations of the owners of tokens and digital currencies. The concepts of the digital law and digital money are designated. Digital law is the rights to objects of civil rights, except for intangible benefits, certified by "a set of the electronic data (digital code or designation) existing in an information system that meets the statutory criteria of a decentralized information system". "Digital money can be a set of the electronic data (a digital code or a designation), non-certifying right to an object of civil rights, created in the information system that meets the statutory criteria of a decentralized information system and is used by the users of this system for making payments" [19].

Tokens are the subjects of the concept of digital law, and digital currencies - of the concept of digital money. These provisions make it possible to expand the use of crypto currencies and tokens in economic circulation, which will remove obstacles from the development of blockchain technology.

Let us consider the directions of the use of blockchain in real estate in more detail.

Acquisition of real estate for digital currency. Buying real estate for crypto currency, bypassing banks, is already happening, mainly, abroad. The first deal on the sale of real estate for bitcoins was issued in 2012 in Israel [20]. As early as in 2014, houses in Bali, Kansas, and California were sold for bitcoins. 
In Russia, ruble is the official means of payment that, however, does not prevent the possibility of exchanging real estate for digital currency, as some kind of intangible entity. The question of nature of the transaction can be resolved as an exchange transaction, but the difficulty is that in the contract of sale it is necessary to indicate the price expressed in rubles. Exchange, carried out in this case with the crypto currency, will have an informal character, which creates significant difficulties, especially in connection with the irrevocable nature of the digital money payment. This issue can be solved with the help of a smart contract, that is, a program that ensures the crediting of funds under the transaction after the fulfillment of all conditions.

Also, a smart contract can help with the acquisition of an object under construction. The buyer can deposit money to the escrow account in the blockchain. After the new building is commissioned and the buyer gets the property right, the money for the developer will be automatically unlocked with the help of the smart contract [21]. This money the developer would not be able to use for construction or other purposes, but will have a guaranteed sale of the constructed real estate.

Exchange of real estate for digital currencies, in our opinion, will allow:

- increasing effective demand on the real estate market;

- involving the crypto assets obtained as a result of mining in the circulation, which will help to reduce the volatility of the crypto currencies, and also expand the scope of their use;

- reducing the cost of rental safes and other costs associated with the transactions.

In the near future, it is expected that the blockchain will be used not only to pay for transactions in crypto currency, but also for transferring conventional (fiat) money via crypto currency to other regions when buying real estate with a significantly lower commission in comparison with available payment services.

To spread the practice of acquiring real estate using digital currencies, it is necessary to introduce crypto currency into the legislative field.

2. Transfer of the document circulation and conclusion of transactions on the blockchain.

Transactions between the seller and the buyer are supposed to be concluded with the help of the blockchain platforms that will increase transparency, reliability and ensure the acceleration of the document circulation when buying real estate.

The ATLANT platform is one of such projects that create a system through which it is possible to conduct $p 2 p$ real estate transactions, bypassing intermediaries. As the authors of the ATLANT project write in the White Paper, using the platform, two basic functions will be realized that allow solving current problems on today's global real estate markets: the tokenization of property rights and $\mathrm{p} 2 \mathrm{p}$ rental [8]. In Russia, this platform is used by the Russian company "33 Elephants", which deals with the registration of real estate transactions in the United States.

3. Transfer of the real estate register to the blockchain.

It solves the problem of ensuring the safety of the real estate registers. The case of the complete loss of the property register in Ghana during an earthquake is widely known. A similar case occurred in the Moscow region town of Dolgoprudnyi, where the book of the cadastral registration for 400 plots of land that had been transferred to private ownership in the 1990s disappeared. Accordingly, the property rights of all people who now own these plots of land and houses, including those who have bought them recently, have been questioned. Fixing property rights to real estate in the distributed registry can solve similar problems.

Since 2016, the projects on transfer of the registers to the blockchain system have been carried out in a number of countries.

In Georgia, in 2017, the company BitFury, a software provider, the National Agency the Public Registry of Georgia, the economist Hernando De Soto and Blockchain Trust Accelerator launched a pilot project on the cadastral registration of real estate on the basis of 
blockchain. In the blockchain, there are almost 200 thousand records of rights of the land plots, transactions are carried out by the blockchain customers and records are available for review to the auditors [22].

In June 2017, Bitfury and the State Agency for the Electronic Government of Ukraine signed a memorandum on the transfer of the state land cadaster of Ukraine to the blockchain, after that a resolution was passed on the transfer of the State Land Cadaster of Ukraine to the blockchain. Both projects will be developed on the Exonum platform [23].

In Ghana, in 2016, the Bitland project, with the official permission of the government, launched the compilation of the land cadaster based on the Bitshares blockchain on the Graphene platform. CADASTRAL tokens have been issued, with the help of which it will be possible to register land rights, resolve disputed land tenure issues, sell and buy land. In Honduras, in 2016, a joint project of the Government was launched with the company Factom on the use of blockchain to register land rights [24].

In 2016, the project of transferring cadastral operations to the blockchain started in Sweden that involves the state Swedish National Land Administration Service, the local blockchain start-up Chromaway, the consulting firm Kairos Future and the telecommunication provider Tellia [25]. The technology of smart contracts is used. Data entry and viewing are available to a limited number of participants.

In Russia, the Russian Registry (Rosreestr) and Vnesheconombank are conducting a competition on the blockchain decisions in the field of registration of real estate. In September 2017, Sberbank announced a pilot blockchain project on the real estate transactions in the city of Velikii Novgorod.

The "blockchainization" of register will reduce the transaction costs by decreasing the number of intermediaries, and reducing the costs of maintaining the state register and cadastral chambers. The creation of "the blockchain passport" of each property becomes possible that will indicate its technical characteristics. This will simplify and accelerate the valuation of real estate.

Problems with transferring the registry to the blockchain. The application of a fully decentralized property register under the title system of the property rights is impossible. Registration of real estate ownership is carried out with the help of the state, until a new solution is found. Therefore, centralization will remain that to some extent contradicts the essence of the distributed registry. Also, in the mentioned above projects (Ukraine, Sweden, and Georgia) proprietary, that is, private registries will be used, that, in our view, has a certain danger. In addition, the concentration of many issues of "blockchainization" of the registry within just one company (in Georgia) is not a merit of the project. The information on the cost of making blockchain in order to assess the economic efficiency of projects is unknown.

The next problem that can arise over time is the compatibility of the existing computer hardware and software with those ways of storing information that will come to replace the existing ones in 10 or more years. It can be solved by transferring information to the new information stores.

4. Tokenization of real estate.

Tokenization of real estate represents the release of tokens, indicating the right to a part of the property. Such projects are called ICO - Initial Coin Offering, they provide for the release of tokens, which give the right to the rights provided under ICO.

Tokenization of real estate is one of the most interesting, but also complex, directions. Tokenization allows involving a large number of people in the purchase of real estate. This can be a method of joint investment in the construction of real estate with granting rights to the subsequent acquisition of a part of the property to the ownership, or the right to its longterm lease in accordance with the rules specified in the contract.

The use of tokens makes it possible to convert the economic value of real estate objects into a more liquid form. In fact, in this case tokens will serve as a mortgage, which will be 
used in the economic turnover. This will increase the effectiveness of ownership of real estate by involving the unused resources in the economic turnover. It is possible to provide a loan secured by a token for real estate.

Tokenization of real estate can significantly stabilize crypto-economy, reduce the volatility of the digital currency market by ensuring tokens with real estate, and will increase the capitalization of crypto-economy. The need to strengthen crypto-market is, in our opinion, an important part of ensuring the stability of the work of the blockchain technologies, because decentralized networks of blockchains are supported by digital currencies. Excessively high volatility of crypto currencies reduces the interest of the networks' participants (they are called miners) to take part in this system.

In working with tokens, it is important to consider different types of tokenization. Tokens issued for obtaining the right to purchase a property in the future or the rights to lease are called "Utility" (a useful token that gives the right to receive a product of a company). In fact, the Utility tokens provide the right to receive rights to the goods (real estate object) or service (rent). There are problems connected with the issue of the transfer of ownership of the property to the owner of the token. Obtaining real rights to real estate in the countries using the title system Torrens, requires passing the registration procedure for making changes to the register. The absence of such registration means that there is no real provision of tokens with real estate. At this stage, the issue has not been resolved. Therefore, it is not always realistic to provide a token with real estate, as it is stated in the ICO. Here there is an analogy with shared construction, when the right to a right is offered, which, in fact, cannot yet be guaranteed.

As an alternative to solving the problem, an example of the Bloquid project, which is led by V. Kislyi, can be used. In this project, the release of the token is made after concluding two contracts with the real estate owner: a token loan contract, and a real estate pledge contract to secure obligations under the loan agreement. After the state registration of the encumbrance of real estate, the smart contract releases tokens. These tokens are transferred to the owner of real estate under a loan agreement. To remove the burden, the borrower must return the tokens, and this gives a link between the value of the collateral and the nominal value of the issued tokens. The provision of tokens is guaranteed by the real estate registry [23].

Another option of tokenization is the issue of tokens for obtaining a share in the income of the company owning real estate from letting out the property, which does not require registration of the right to a share of real estate in the state register. Such a token is called "Security", it is an investment token. In the US law, it is equated with securities and is subject to their regulation. In Russia, the status of tokens in general, as well as their options, is not legally defined.

It should be noted that tokenization and ICO, due to the novelty and institutional unsettledness, still contains a lot of scams, that is, empty projects, which cannot or will not be implemented, that undermines confidence to the tokenization as a whole. But this is the payment for carrying out economic experiments, and testing new tools for working with the blockchain economy.

5. Other ways of using the blockchain technology and crypto currencies in real estate.

In the joint operation of real estate, mutual decisions are made by the means of voting, those are for major repairs, intercoms, and communications. In general, p2p voting is the level of blockchain 3.0 [167]. Voting on the blockchain can be a convenient form for recording votes of all property owners, and not only those who participate in the meetings.

Maintenance of the blockchain is carried out by computer devices that perform calculations and cryptographic encryption of transactions (proof of work - PoW). This is accompanied, on the one hand, by the production of crypto currency by the miners, and on the other hand by the release of heat, which can be used to heat houses or other premises 
where this equipment is installed. It is conditioned by the availability of the Internet, good quality of power supply and relatively low cost. The received digital currency can compensate a part of the cost of the real estate object and reduce expenses for heat. The technological solution of this problem has not yet been perfected, but it is already possible doing it. This is a way of using not only the blockchain itself, but the by-products of its functioning, as a result of which the real estate becomes cheaper.

Let us designate the problems of introducing blockchain to the real estate market.

1. The problem of legal consolidation of the status of the digital currencies. The technology's capabilities outstrip the state response, and the legal framework regulating the use of the blockchain has not yet been created. Many advantages of distributed registries can be realized only after the appearance of such a base, which will allow, for example, to protect smart contracts and other operations carried out on the blockchain in the court. Here one should not rush, as it is very easy to make erroneous assumptions that will lead to the flow of the blockchain technologies and digital currencies to other jurisdictions that would be more loyal.

2. High costs for transferring ordinary capital (fiat) to the digital currency and vice versa: fees for withdrawal of funds to the MasterCard or Visa cards vary from $0.5 \%$ to $5 \%$. Most likely, this problem will disappear with time. Even now, several start-ups say they will be able to reduce the commission to zero.

3. "Know your customer" procedure (KYC). Most likely, the owners of digital capital, as well as other investors, will have to undergo standard procedures for checking the sources of money, which is technically difficult to implement today. The Russian banks obliged by law to check the origin of money are not ready to work with the owners of the crypto currency, and this is typical for many foreign banks [24, 26].

4. A high proportion of the scam, i.e. unfair or unrealized ICO projects that undermines confidence in the possibilities of property tokenization.

5. The population of Russia is almost not familiar with digital currencies and the mechanism of working with them. Therefore, a huge work is required on digital education.

Further development of research on the use of blockchain should answer the following questions:

1. What institutional regulation of crypto-economics and tokenization will be the most useful for the real estate market development?

2. What kind of economic effect does tokenization bring (on the example of specific projects)?

3. What are the consequences of transferring real estate registers to the blockchain in terms of cost savings for maintaining the real estate registry and the benefits received by real estate consumers?

4. How to ensure the rights of consumers in the course of property tokenization, including protection from the scam in the ICO projects?

The study of these issues and the choice of ways of institutional regulation, enabling the development of blockchain and crypto-economics on the real estate market will improve the efficiency of a very important market, and increase the availability of housing, which is still a big issue in Russia.

\section{References}

1. N. Axford, Global investor intentions survey (http://www.cbre.com/research-andreports/Global-Investor-Intentions-Survey-2017, 2017)

2. Statistics of the Irkutsk region in 2016 (http://irkutskstat.gks.ru, 2018)

3. M. A. Yakovleva, Structure of the Modern World Economy, 13 (2017) 
4. N. Ya. Kalyuzhnova, Fundametal Research, 11-2, 251-255 (2013)

5. T. Egertson, Economic behavior and institutions (Case, Moscow, 2001)

6. D. North, Institutions, institutional changes and functioning of the economy (Elements, Moscow, 1997)

7. The average term for the sale of an apartment in Moscow has reached 4 months (https://realty.rbc.ru/news/58b53e399a79477ec21a9792, 2018).

8. S. Gabov, Block and real estate: reality and prospects (http://elitetrader.ru/index.php?newsid=391794)

9. ATLANT platform; white paper (https://atlant.io/assets/documents/en/Atlant_WP_ publish.pdf, 2018)

10. K. Schwab, The fourth industrial revolution (Eksmo, Moscow, 2016)

11. K. Sinner, WalueWeb, (Mann, Ivanov and Ferber, Moscow, 2018)

12. V. Morabito, Business Innovation Through Blockchain, 69 (2017)

13. F. Fukuyama, Trust: the social virtues and the creation of prosperity (Hamish Hamilton, London, 1995)

14. Christian Bjørnskov,), Southern Econ. J., 78(4), 1346-68 (2012)

15. N. Ya. Kalyuzhnova, Economy of the Region, 1 (2014)

16. V. Sour, Applying technology blockade in real estate (https://zakon.ru/blog/2017/9/20/ primenenie_tehnologii_blokchejn_v_nedvizhimosti, 2018)

17. U. Moghayar, Blokchein for business (Eksmo, Moscow, 2018)

18. M. Swan, Blokchein: Scheme of a new economy (Olimp-Business, Moscow, 2017)

19. The draft on Amending Part One, Two, and Four Civil Code of the Russian Federation (http://www.garant.ru/hotlaw/federal/1187665, 2018)

20. Kryptonite for the economy (http://new.cre.ru/eng/archivnews/0/0/56954, 2018)

21. I. Kalganov, Blocking (https://realty.rbc.ru/news/59ba787e9a79477ae173aa7b, 2018)

22. Bitfury signed a memorandum on the introduction of blockade technology in Georgia (https://forklog.com/kompaniya-bitfury-podpisala-memorandum-o-vnedreniitehnologii-blokchejn-v-gruzii, 2018)

23. Blocking in the land cadastre of Ukraine: positive moments and pitfalls (https://forklog.com/blokchejn-v-zemelnom-kadastre-ukrainy-polozhitelnyemomenty-i-podvodnye-kamni, 2018)

24. L. A. Stepanova, D. T. Annan, Bulletin of Tver State Technical University, 1, 3-7 (2018).

25. J. Young, Sweden officially started using blockchain to register land and properties (https://cointelegraph.com/news/sweden-officially-started-using-blockchain-toregister-land-and-properties, 2018)

26. Y. V. Ragulina, A. V. Bogoviz, A. N. Alekseev, Advances in Intelligent Systems and Computing, 622, 568-573 (2018) 